\title{
Uncertainty analysis for estimates of the first indirect aerosol effect
}

\author{
Y. Chen and J. E. Penner \\ University of Michigan, Department of Atmospheric, Oceanic and Space Sciences, Ann Arbor, USA
}

Received: 13 May 2005 - Published in Atmos. Chem. Phys. Discuss.: 6 July 2005

Revised: 30 September 2005 - Accepted: 26 October 2005 - Published: 4 November 2005

\begin{abstract}
The IPCC has stressed the importance of producing unbiased estimates of the uncertainty in indirect aerosol forcing, in order to give policy makers as well as research managers an understanding of the most important aspects of climate change that require refinement. In this study, we use 3-D meteorological fields together with a radiative transfer model to examine the spatially-resolved uncertainty in estimates of the first indirect aerosol forcing. The global mean forcing calculated in the reference case is $-1.30 \mathrm{Wm}^{-2}$. Uncertainties in the indirect forcing associated with aerosol and aerosol precursor emissions, aerosol mass concentrations from different chemical transport models, aerosol size distributions, the cloud droplet parameterization, the representation of the in-cloud updraft velocity, the relationship between effective radius and volume mean radius, cloud liquid water content, cloud fraction, and the change in the cloud drop single scattering albedo due to the presence of black carbon are calculated. The aerosol burden calculated by chemical transport models and the cloud fraction are found to be the most important sources of uncertainty. Variations in these parameters cause an underestimation or overestimation of the indirect forcing compared to the base case by more than $0.6 \mathrm{Wm}^{-2}$. Uncertainties associated with aerosol and aerosol precursor emissions, uncertainties in the representation of the aerosol size distribution (including the representation of the pre-industrial size distribution), and uncertainties in the representation of cloud droplet spectral dispersion effect cause uncertainties in the global mean forcing of $0.2 \sim 0.6 \mathrm{Wm}^{-2}$. There are significant regional differences in the uncertainty associated with the first indirect forcing with the largest uncertainties in industrial regions (North America, Europe, East Asia) followed by those in the major biomass burning regions.
\end{abstract}

\footnotetext{
Correspondence to: Y. Chen

(ychenz@umich.edu)
}

\section{Introduction}

Although there has been a large amount of progress in the development of the study of aerosol effects on the global climate, uncertainty in the estimation of the indirect aerosol forcing remains one of the highest in the climate studies today (Ramaswamy et al., 2001; Lohmann and Feichter, 2005). This is partly due to the high temporal and spatial inhomogeneity in aerosol concentrations and partly due to the complex relationship between the aerosol chemical and physical properties and cloud microphysics.

Aerosols influence cloud radiative properties in several ways. The first and the most widely studied is that aerosol particles increase the cloud droplet number concentration and decrease the cloud effective radius, thereby modifying the cloud optical properties. This effect is called the First Indirect Effect (or Radius Effect) and was first estimated by Twomey (1974). The other effect is that the decreased cloud droplet effective radius decreases the rate of autoconversion and inhibits precipitation formation, causing longer cloud lifetime and higher cloud amount. This effect is called the Second Indirect Effect (or Lifetime Effect) and its recognition is commonly attributed to Albrecht (1989). The existence of absorbing particles (such as black carbon) may have other indirect effects, related to the heating of air and cloud evaporation (the so-called Semi-direct Effect) (Graß1, 1979; Conant et al., 2002) which can change the vertical temperature profile and the dynamical structure of clouds (Hansen et al., 1997; Ackerman et al., 2000; Penner et al., 2003), and can modify the cloud droplet single scattering albedo when the absorbing aerosols are in the cloud droplet (Chuang et al., 2002).

There are a number of estimates of the global indirect aerosol forcing in the literature (Kiehl et al., 2000; Lohmann et al., 2000; Ghan et al., 2001; Iversen et al., 2001; Jones et al., 2001; Rotstayn and Penner, 2001; Menon et al., 2002; Kristjánsson, 2002; Chuang et al., 2002). In most of these

(C) 2005 Author(s). This work is licensed under a Creative Commons License. 
calculations, the prescribed or simulated aerosol field is related to cloud droplet number concentration through empirical or physically-based parameterizations. Many of these models also account for the influence of the change in cloud droplet effective radius on the autoconversion rate. Although all of the calculations of first indirect aerosol forcing have a negative sign, their values can range from -0.5 to $-1.85 \mathrm{Wm}^{-2}$ as summarized in Penner et al. (2001). This is much larger than the uncertainty in green house gas forcing, which is $2.2 \sim 2.7 \mathrm{~W} / \mathrm{m}^{2}$ (Ramaswamy et al., 2001). An accurate estimation of aerosol effects on climate is important not only to research priorities, but also to constrain estimates of forcing that are consistent with observations of the historical temperature range (Penner, 2004).

The IPCC has stressed the importance of producing unbiased estimates of the uncertainty in aerosol indirect forcing, in order to give policy makers as well as research managers an understanding of the most important aspects of climate change that require refinement. However, not much has been done to quantify the uncertainty in the indirect aerosol forcing calculation. The reported range of uncertainty in the IPCC report (Ramaswamy et al., 2001) and the summary for policy makers (Houghton et al., 2001) has mainly relied on uncertainties associated only with the range of results in literature, and are based on "expert judgment". Penner et al. (2001) used a simple box-model and an empirical relationship between sulfate aerosol concentration and droplet concentration (Boucher and Lohmann, 1995) to study the uncertainty in indirect aerosol forcing. Their analysis leads to an overall estimate for indirect forcing from fossil fuel-related aerosols of $-1.4 \mathrm{Wm}^{-2}$ with a $67 \%$ confidence interval of from 0 to $-2.8 \mathrm{Wm}^{-2}$. However, this uncertainty analysis does not give any spatial information that might guide future research priorities or aircraft missions, nor does it establish separate uncertainty ranges for biomass aerosols and for fossil fuel aerosols.

In the present study, we use 3-D meteorological fields together with a radiative transfer model to examine the spatially-resolved uncertainty in estimates of indirect forcing. The forcing of anthropogenic sulfate and carbonaceous aerosols is calculated, and the effect of natural aerosols species which act as cloud condensation nuclei is included in the simulation. We consider each uncertainty source in the calculation of indirect aerosol forcing, including those that arise from the specified or assumed aerosol properties, the specified aerosol-cloud droplet relationship, and the relation between the cloud droplet effective radius and volume mean radius. We only consider physically-based cloud nucleation parameterizations as opposed to empirically-based parameterizations, since only the former can be applied to all aerosols. Our aim is to determine what aspect of the indirect uncertainty forcing calculation for the first indirect effect is the most uncertain and in which spatial regions the uncertainty is largest. The method of calculation and the sources of uncertainty are discussed in Sect. 2. The results, including the calculated cloud effective radius and the forcing uncertainty, are presented in Sect. 3. Section 4 presents a discussion and our conclusions.

\section{Methodology}

\subsection{Experimental design}

In this study, we use the model-averaged monthly mean aerosol mass concentrations developed from the IPCC aerosol model inter-comparison (Penner et al., 2001; Zhang, 2003). In addition to sulfate aerosols, we also include sea salt, dust, organic carbon (OC), and black carbon (BC). The aerosols are assumed to be internally mixed. The mass concentrations are converted to number concentration by an assumed log-normal size distribution. We vary the mean radius and standard deviation to consider the uncertainty related to this assumption. These number concentrations are used to calculate the cloud droplet number concentration using different cloud nucleation parameterizations. In addition, different options for specifying the in-cloud updraft velocity are used.

The effective radius of the cloud droplet is related to cloud droplet number concentration by $r_{e}=\beta r_{v}=\beta\left(\frac{3 L W C}{4 \pi \rho_{w} N_{d}}\right)^{\frac{1}{3}}$, where $\beta$ is a coefficient which relates the cloud droplet effective radius $\left(r_{e}\right)$ to the volume mean radius $\left(r_{v}\right)$ (Martin et al., 1994). This 3-D effective radius field is input to a radiative transfer model for the radiative calculation. The radiation transfer model is based on the shortwave radiative code developed by Grant et al. (1998). For warm clouds, the optical depth, single scattering albedo, and asymmetry factor are parameterized as a function of cloud effective radius. The ice cloud effective radius is assumed to be fixed at $40 \mu \mathrm{m}$. The cloud overlap scheme used is a maximum-random overlap scheme, i.e., continuous cloud layers are assumed to be maximally overlapped, while discontinuous cloud layers are randomly overlapped (Geleyn and Hollingsworth, 1979; Feng et al., 2004). The meteorological data are the 2000 GEOS-3 data from NASA Data Assimilation Office (DAO).

To calculate the radiative forcing with anthropogenic aerosols, two sets of radiative calculations are made, one with pre-industrial (PI) aerosols and one with present day (PD) aerosols. The difference in the TOA net incoming flux between these two scenarios is the anthropogenic aerosol indirect forcing. In the radiative calculation, the aerosol concentrations and distributions are assumed at their present day values while allowing the present day and pre-industrial aerosols to only affect the calculation of the cloud droplet number concentration, to make sure that the direct aerosol radiative scattering/absorption is the same in the PI and PD. In this study, the cloud microphysics is calculated once every six hours, and the radiative flux is calculated once per hour. Since the meteorological fields are from an offline 
calculation, we only consider the First Indirect Effect. However, we include the change in the cloud single scattering albedo caused by treating the in-cloud presence of absorbing aerosols in one perturbation case.

\subsection{Sources of uncertainty}

A flowchart of the parameters needed to calculate the indirect aerosol forcing and the sources of uncertainties is presented in Fig. 1. The sources of uncertainty include the aerosol and aerosol precursor emissions, the aerosol mass concentrations for a given source inventory calculated from a chemical transport model, the aerosol size distribution, the cloud nucleation parameterization, the method of determining the in-cloud updraft velocity, the relationship between effective radius and volume mean radius, the cloud liquid water content, the cloud fraction, and the change of cloud radiative properties associated with the presence of BC. In this study, we perturb each of these parameters and calculate the difference in the indirect aerosol forcing associated with each perturbation. For some parameters, the uncertainty in the radiative forcing is calculated by simulating both the maximum and minimum cases. For other parameters, we only consider different options for treating the indirect effect. In the following, we give an introduction to the different sources of uncertainties.

The IPCC aerosol inter-comparison project which is used to estimate the uncertainty associated with the aerosol mass concentration (see next paragraph) is based on a fixed set of aerosol and aerosol precursor emissions. However, there are uncertainties related to the emission of the aerosols and their precursors. Here we adopt the low and high values of the anthropogenic emissions from Tables 5.2 and 5.3 in Penner et al. (2001) (which reflect estimates reported in the literature) as a measure of the $1 \sigma$ limit of the emissions uncertainty. Because the aerosol concentrations were almost linearly related to their emissions in the models used in the IPCC intercomparison, we scaled the aerosol mass concentrations by the ratio of the maximum or minimum emissions to the mean emissions. The calculated forcing based on the aerosol mass after scaling and before scaling is used to estimate the variance due to the emissions of aerosols and aerosol precursors.

The estimate of the mean, maximum, and minimum global aerosol mass concentrations was based on the IPCC Aerosol Model Inter-comparison (Penner et al., 2001; Zhang, 2003). Eleven aerosol chemical transport models participated in this inter-comparison. The output aerosol species from these models included natural sulfate (nSO4), anthropogenic sulfate (aSO4), natural and anthropogenic organic carbon (OC), anthropogenic black carbon (BC), dust and sea salt. Natural $\mathrm{BC}$ was not specified in the IPCC Aerosol Inter-comparison but was estimated here from the anthropogenic $\mathrm{BC}$ and a monthly averaged scaling factor, which was derived from

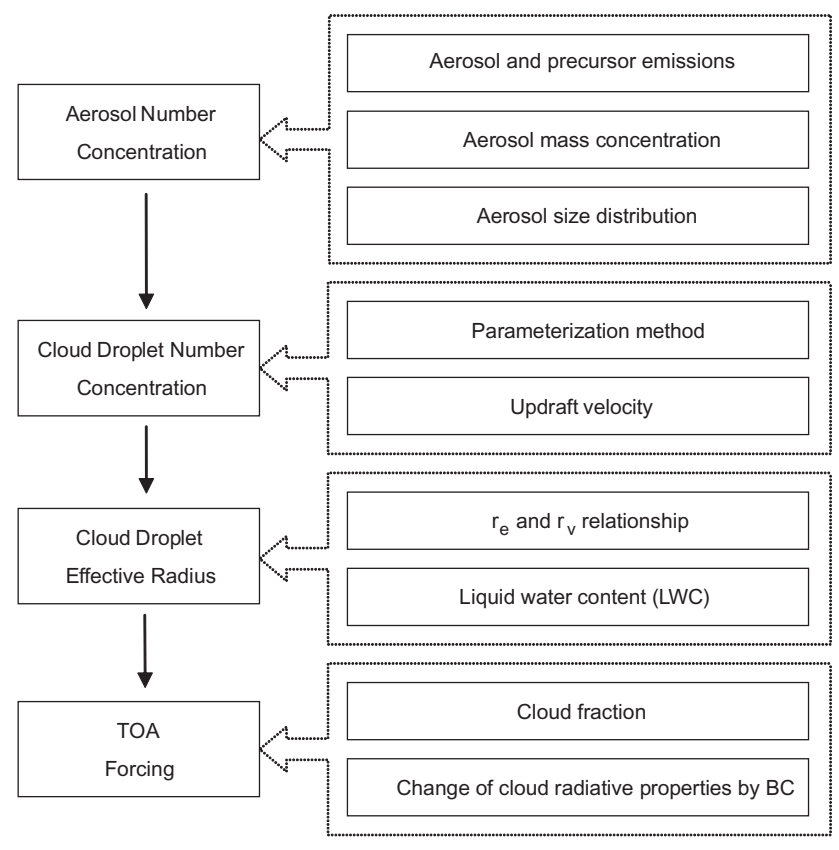

Fig. 1. List of sources in the calculation of indirect aerosol forcing. The left part shows the main parameters in the aerosol effects on clouds and climate. The right part shows the sources of uncertainty.

the GMI model aerosol simulations (Liu et al., 2005 ${ }^{1}$ ). In this study, the monthly mean aerosol concentrations approximately represented the year 2000. For the pre-industrial case, the total aerosol mass is the sum of natural sulfate, natural organic aerosols (POM), dust and sea salt. For present day case, the total aerosol mass concentration is the sum of all aerosols. To be consistent with the aerosol size used later, only sub-micron dust and sea salt are considered. The reference case is calculated using the model-average aerosol mass concentration from those models whose concentrations were in reasonable agreement with observations (Penner et al., 2001). To calculate the uncertainty associated with the aerosol mass concentrations associated with the chemical transport model, the maximum and minimum aerosol concentrations from these models were used in the perturbation case.

To provide a uniform platform for different cloud nucleation parameterizations, a single mode log-normal size distribution for the aerosol was assumed. The reference mode radius and geometric standard deviation of both continental and marine aerosols are taken from the central values determined from a literature search (Penner et al., 2001). The uncertainties in the mode radius and geometric standard deviation are considered in the calculation of forcing uncertainty.

\footnotetext{
${ }^{1}$ Liu, X., Penner, J. E., Das, B., Bergmann, D., Rodriguez, J. M., Strahan, S., Wang, M., and Feng, Y.: Uncertainties in global aerosol simulations: Assessment using three meteorological datasets, J. Geophys. Res., submitted, 2005.
} 
These uncertainties are also based on the ranges of values in the literature as summarized in Penner et al. (2001). The mode radius and $1 \sigma$ ranges were $0.05 \pm 0.04 \mu \mathrm{m}$ (over land) and $0.095 \pm 0.015 \mu \mathrm{m}$ (over ocean). The geometric standard deviation ranges were $1.9 \pm 0.3$ (over land) and $1.5 \pm 0.15$ (over ocean). Since the effect of size distribution on the forcing is non-linear, we used both the maximum and minimum values of the mode radius and standard deviation in our tests. Except for one case (see below), the same values were used in our uncertainty analysis for both the present day and preindustrial aerosols.

The above measurements actually summarize the size distribution of the present day aerosol. But there are large uncertainties associated with the size of the pre-industrial aerosols. The anthropogenic aerosol may form by condensation onto pre-existing aerosols, and therefore, would not change the aerosol number but would increase the aerosol size (Chuang et al., 1997). If this assumption is correct, a different choice with a smaller pre-industrial aerosol should be used to examine the uncertainty of the indirect forcing. For this case we assumed that the mean size and standard deviation of free troposphere aerosol $\left(r=0.036 \mu \mathrm{m}, \sigma_{g}=2.2\right)$ from Penner et al. (2001) were the appropriate size distribution parameters of the pre-industrial continental aerosol.

Currently, there are two categories of approaches to relate the aerosol properties (concentration, size and composition) to the cloud microphysical properties (number concentration and effective radius). Some researchers used an empirical relationship between cloud droplet number and aerosol mass concentration (Boucher and Lohmann, 1995; Lohmann and Feichter, 1997; Roelofs et al., 1998), or number concentration (Jones et al., 1994; Menon et al., 2002; Suzuki et al., 2004). These methods are based on observations and are easy to use in global forcing calculations, but they do not reflect the physical and chemical processes that occur during cloud nucleation, which depend on the size, chemical composition of the aerosol, as well as the updraft velocity. In addition, they are based on measurements at particular places and times, and so may be biased if they are used a global calculation or used to project future scenarios. Therefore in this study, only cloud nucleation parameterizations based on a mechanistic parameterization of nucleation are used. Three mechanistic parameterizations have been used to calculate the cloud droplet number concentration: Chuang et al. (1997) (hereafter CP); Abdul-Razzak and Ghan (2002) (hereafter AG3); and Nenes and Seinfeld (2003) (hereafter NS). The relationship between cloud droplet number and aerosol number from these different parameterizations has been tested and compared to detailed parcel model simulation results (see Appendix A). Based on the results presented in Appendix A, the AG3 parameterization is closest to the results of parcel model. So in this study, we chose the AG3 parameterization as the method used in the reference case. And we examined the results from the other parameterizations in the perturbation cases.
The large scale vertical velocity in a General Circulation Model (GCM) does not resolve sub-grid variations and it is these variations that determine cloud droplet nucleation (Feingold and Heymsfield, 1992). To estimate the in-cloud updraft velocity, two approaches are used. The first approach (hereafter PDF) uses a normal probability distribution with the GCM-predicted vertical velocity as the mean value and a prescribed standard deviation (Chuang et al., 2002). Chuang et al. (1997) used a value of $50 \mathrm{~cm} / \mathrm{s}$ for the standard deviation of the updraft for warm clouds based on measured updrafts in stratiform clouds (Paluch and Lenschow, 1992) and argued that the sensitivity of indirect forcing to this value is small. Another method that has been used to estimate the amount of sub-grid variation of the updraft velocity is to use the GCM model-generated turbulent kinetic energy (TKE). By assuming that the sub-grid vertical velocity variability is dominated by the turbulent transports and by choosing the root-mean-square value of TKE as a measure of this, the in-cloud updraft velocity could be expressed as $w=\bar{w}+0.7 \sqrt{T K E}$, where $\bar{w}$ is the GCM-resolved large scale updraft velocity (Lohmann et al., 1999a; Lohmann et al., 1999b). Using a single updraft velocity for the entire grid cell is a simplification, since the updraft velocity varies over the grid cell (Lohmann et al., 1999b). In this study, we use the PDF approach in the reference case and the TKE approach in the perturbation case.

As stated above, the effective radius $\left(r_{e}\right)$ is related to the volume mean radius $\left(r_{v}\right)$ by the coefficient $\beta$. According to Martin et al. (1994), the value of $\beta^{-3}$ is $0.67 \pm 0.07$ and $0.80 \pm 0.07$ over the land and ocean, respectively. In the reference case, a fixed coefficient for $\beta$ equal to 1.12 over both land and ocean is used to account for the relationship between the effective radius and the volume mean radius. However, alterations in the linear relationship between $r_{e}$ and $r_{v}$ are expected in the presence of entrainment, precipitation, and ice particles (Andronache et al., 1999). Recently, Liu and Daum (2002) showed that the dispersion of the cloud droplet spectrum is related to the cloud droplet number concentration. They argued that the effect of dispersion on the reflected radiation may substantially negate the effect due to increasing cloud droplet concentration. Based on their results, Penner et al. (2004) presented a parameterization of this coefficient as a function of cloud droplet number concentration: $\beta=\left(5.0 \times 10^{-4} \times N_{d}+1.18\right)^{-1 / 3}$. Therefore we considered this option for expressing $\beta$ in a perturbation case to examine the uncertainty associated with the calculation of $r_{e}$. Rotstayn and Liu (2003) examined three different relationships between $\beta$ and $N_{d}$, and estimated the sensitivity of the first indirect aerosol effect to these different expressions of dispersion term. In this study, we also examined the sensitivity of the indirect effect to the use of the relationships given in Rotstayn and Liu (2003).

If the droplet number concentration is fixed, the effective radius of cloud droplets is directly linked to the cloud liquid water content. Liquid water path (LWP) is the vertical 
Table 1. Comparison of annual average Cloud Fraction (CF) and Liquid Water Path (LWP) used in reference case from the parameterization and satellite measurements. MODIS data are for the year 2000. Other data are for the year 1997.

\begin{tabular}{ccccccccc}
\hline & para, all & ISCCP, all & MODIS, all & SSM/I, all & para, low & ISCCP, low & para, warm & MODIS, warm \\
\hline CF & 0.8 & 0.67 & 0.61 & 0.47 & 0.48 & 0.27 & 0.48 & 0.52 \\
LWP & 64.2 & 72.9 & & $48.9^{*, a}$ & & & 51.3 & 95.3 \\
$\left(\mathrm{~g} / \mathrm{m}^{2}\right)$ & & & & $79.5^{*, \mathrm{~b}}$ & & & $59.7^{*}$ & \\
\hline
\end{tabular}

* ocean only

a Retrieved using method of Weng et al. (1994)

b Retrieved using method of Greenwald et al. (1993) all: all sky

low: $\mathrm{p}<680 \mathrm{mb}$

warm: $\mathrm{T}>260 \mathrm{~K}$ integral of the cloud liquid water content (LWC). In the reference case, we used a parameterization that relates the LWP (Hack, 1998) and the cloud fraction (CF) (Sundqvist, 1988) to the RH values from the DAO meteorological fields. To study the effect of LWP uncertainty, we compared the global mean LWP from the parameterization to different LWPs retrieved from satellites, including those from ISCCP, MODIS, SSM/I (see Table 1). Then, we scaled the 3-D LWC by the ratio of the maximum LWP value of the measurements and the model-generated LWP from the parameterization. We also calculated the ratio from the minimum satellite-measured values. These LWC fields after scaling were used to calculate the forcing uncertainty due to LWP uncertainty. In these two cases, we assumed the LWP difference is due only to the in-cloud LWC difference, i.e., we assumed the cloud fraction was the same as in the reference case.

The cloud fraction does not affect the cloud effective radius, but it directly affects the solar radiation reaching the surface. As in the LWP uncertainty study, we compared the $\mathrm{CF}$ fraction from the parameterization to the cloud fraction retrieved from satellites and calculated the maximum and minimum ratio of $C F$ to the parameterized value. Since the $\mathrm{CF}$ from parameterization is larger than the values from all satellites, only the CF parameterization scaled by the minimum ratio is used in the perturbation case. We also note that our radiative transfer scheme uses the maximum random overlap method described in Feng et al. (2004).

Light-absorbing aerosols such as black carbon (BC) can be activated as cloud droplets and their presence in cloud may reduce the single scattering albedo of cloud and change the radiation balance of the atmosphere. Most studies of indirect forcing assume that all of the $\mathrm{BC}$ aerosols are present as interstitial aerosols and this is also assumed in our reference case. In this study, we examined a perturbation case in which the effect of $\mathrm{BC}$ on the cloud optical properties in the present day scenario was considered. The modification of cloud droplet single scattering albedo was based on the parameterization developed by Chuang et al. (2002). Compared to reference case, only the modification of cloud single scattering albedo is considered, and the $\mathrm{BC}$ used to calcu- late aerosol scattering/absorption and cloud nucleation is the same as in the reference case.

Table 2 summarizes the perturbation cases considered in this study. In the central or reference case, most of the variable parameters are set to the mean values, although for some parameters, we arbitrarily select one option to use in reference case: for in-cloud updraft velocity we select the PDF method; for the cloud nucleation parameterization, we select the AG3 method (which is closest to the parcel model simulation); for $\mathrm{BC}$ effect on cloud single scattering albedo, we assume it is not included in the reference case. In all the perturbation cases, only one parameter is changed, in order to calculate the uncertainty in the indirect forcing associated with each parameter.

\section{Results}

\subsection{Reference case results}

Figure 2 shows the zonal mean annual average cloud droplet number concentration $\left(N_{d}\right)$ from the PD scenario in the reference case. There are two regions with large values for $N_{d}$. The region in the northern hemisphere mid-latitudes is due to high aerosol and precursor emissions from industrialized regions, while the high concentration in the 50-60 degree region in the southern hemisphere is mainly due to high sea salt concentrations. $N_{d}$ has its largest values below $900 \mathrm{mb}$, and these decrease with an increase in altitude. In the layers in which low cloud occurs most frequently $(800 \mathrm{mb}-950 \mathrm{mb})$, the zonal average $N_{d}$ is between 50 and $250 \mathrm{~cm}^{-3}$.

Han et al. (1994) reported retrieved $r_{e}$ for liquid-water clouds from ISCCP satellite data. MODIS satellite data have also been used to retrieve the cloud effective radius (King et al., 1997). We compare these data with the $r_{e}$ from our simulations in Table 3. The simulated $r_{e}$ does capture the spatial variations seen in the satellite data. The $r_{e}$ over the SH oceans is $0.7 \mu \mathrm{m}$ larger than that over the NH oceans, compared to $0.6 \mu \mathrm{m}$ from ISCCP. The simulations also show a clear land-sea contrast, although the value of this difference is smaller than that derived from ISCCP and from MODIS. 
Table 2. Name and description of the perturbation cases simulated in this study.

\begin{tabular}{|c|c|}
\hline Name & Description \\
\hline \multirow[t]{10}{*}{ Reference } & Aerosol and precursor emissions: the average emissions used in the IPCC model inter-comparison \\
\hline & Aerosol mode radius: $0.05 \mu \mathrm{m}$ over land, $0.095 \mu \mathrm{m}$ over ocean \\
\hline & Aerosol standard deviation: 1.9 over land, 1.5 over ocean \\
\hline & Aerosol mass concentration: mean values from IPCC model inter-comparison \\
\hline & In-cloud updraft velocity: Probability Distribution Function method \\
\hline & Cloud nucleation parameterization: AG3 method \\
\hline & BC effects on cloud single scattering albedo: Not included \\
\hline & LWP: from parameterization based on DAO RH data \\
\hline & $\mathrm{CF}$ : from parameterization based on $\mathrm{DAO} \mathrm{RH}$ data \\
\hline & Dispersion coefficient $\mathrm{k}$ : fixed single value $=1.12$ \\
\hline MAX_EMI & Aerosol precursor emission: scaled to maximum emission \\
\hline MIN_EMI & Aerosol precursor emission: scaled to minimum emission \\
\hline MAX_R & Aerosol mode radius: $0.09 \mu \mathrm{m}$ over land, $0.11 \mu \mathrm{m}$ over ocean \\
\hline MIN_R & Aerosol mode radius: $0.01 \mu \mathrm{m}$ over land, $0.08 \mu \mathrm{m}$ over ocean \\
\hline MAX_SG & Aerosol standard deviation: 2.2 over land, 1.65 over ocean \\
\hline MIN_SG & Aerosol standard deviation: 1.6 over land, 1.35 over ocean \\
\hline DIST_PI & Natural aerosol size distribution: use the free troposphere aerosol size distribution \\
\hline MAX_MA & Aerosol mass concentration: maximum values from the IPCC model inter-comparison \\
\hline MIN_MA & Aerosol mass concentration: minimum values from the IPCC model inter-comparison \\
\hline W_TKE & In-cloud updraft velocity: $\bar{w}+0.7 \sqrt{T K E}$ \\
\hline PARA_NS & Cloud nucleation parameterization: Nenes and Seinfeld method \\
\hline PARA_CP & Cloud nucleation parameterization: Chuang and Penner method \\
\hline BC_INC & BC effects on cloud single scattering albedo: Included \\
\hline MAX_LWP & LWP: scale the parameterized LWP to maximum based on satellite measurements \\
\hline MIN_LWP & LWP: scale the parameterized LWP to minimum based on satellite measurements \\
\hline MIN_CF & $\mathrm{CF}$ : scale the parameterized $\mathrm{CF}$ to the minimum based on satellite measurements \\
\hline$\beta \_$FND & Dispersion coefficient $\beta$ : the function of cloud droplet number $\left(N_{d}\right)$ specified in Penner et al. (2004). \\
\hline$\beta \_$RLlow & Relationship between $\beta$ and $N_{d}$ : the LOWER simulation by Rotstayn and Liu (2003) \\
\hline$\beta \_$RLup & Relationship between $\beta$ and $N_{d}$ : the UPPER simulation by Rotstayn and Liu (2003) \\
\hline$\beta \_\mathrm{RLmid}$ & Relationship between $\beta$ and $N_{d}$ : the MIDDLE simulation by Rotstayn and Liu (2003) \\
\hline
\end{tabular}

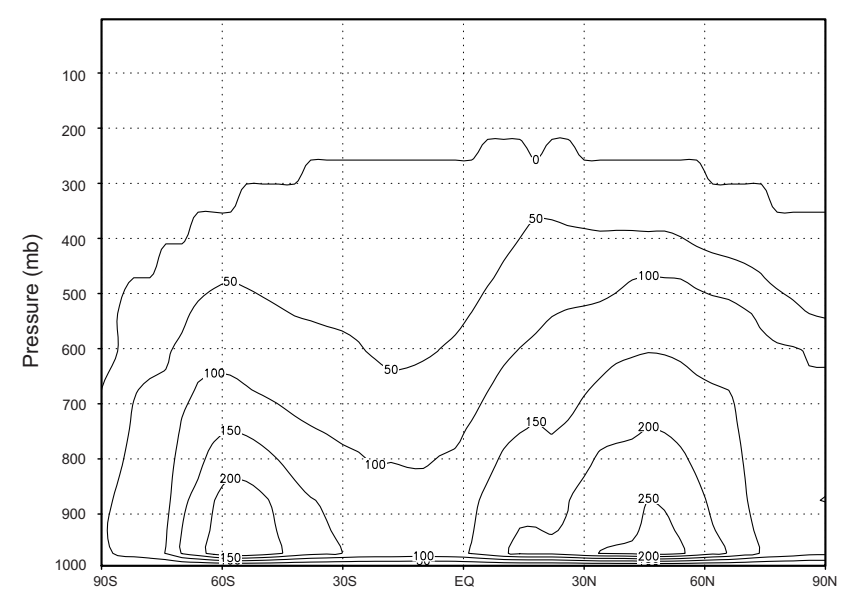

Fig. 2. Zonal mean annual average cloud droplet number concentration $\left(N_{d}\right)$ in the PD in the reference case.
The simulated global mean $r_{e}$ is also smaller than the retrieved data, which may be due to our reference case parameterization of the in-cloud liquid water content. This underestimate of $r_{e}$ is also common to many present GCMs (Quaas et al., 2004). In addition, the measured $r_{e}$ refers only to the cloud-top value of $r_{e}$, whereas the model results in Table 3 refer to the LWC-weighted value of $r_{e}$ above temperature zero. This can partially explain why the modeled effective radius is smaller than retrieved value.We also note that satellite determination of $r_{e}$ is probably no more accurate than a few micrometers (Han et al., 1994).

Figure $3 \mathrm{a}$ and $\mathrm{b}$ show the total anthropogenic and natural aerosol burden while Fig. $3 \mathrm{c}$ shows the simulated change in the cloud droplet number concentration at $875 \mathrm{mb}$ between the PD scenario and the PI scenario. The global distribution of the indirect aerosol forcing resulting from these changes is presented in Fig. 3d. These plots show similarities in their spatial distribution, and demonstrate a clear relationship between anthropogenic emissions and their effects on cloud droplet concentrations and radiative forcing. 

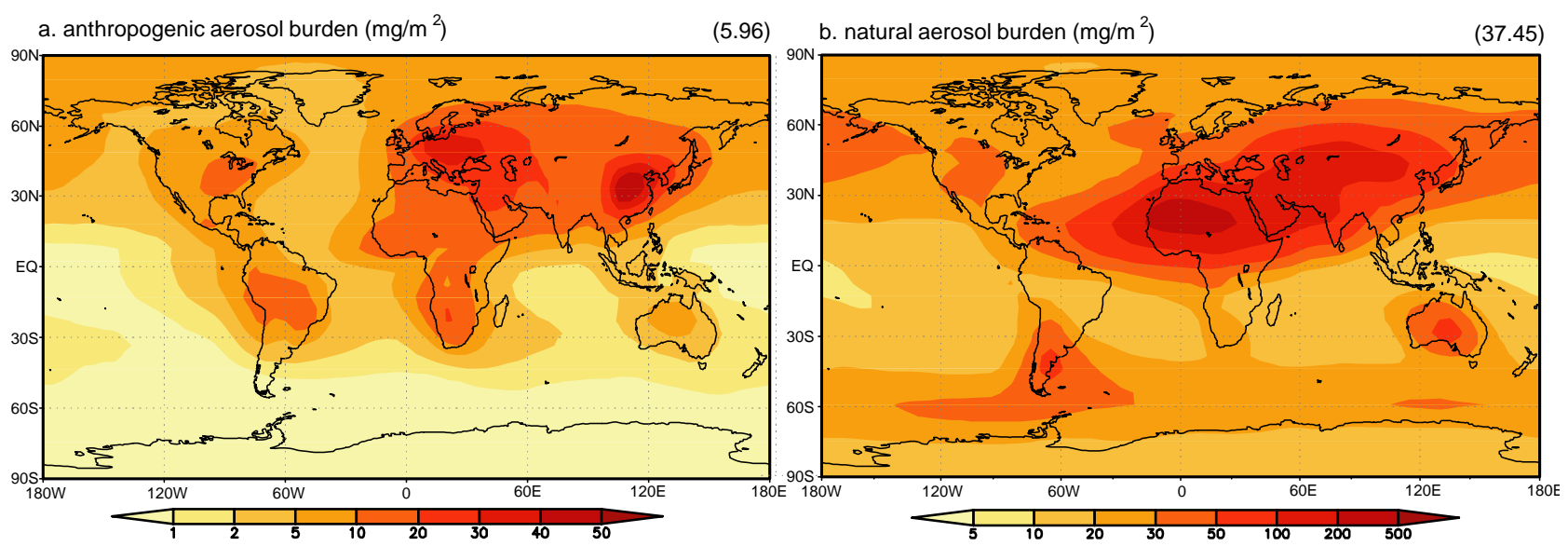

c. droplet number change at $875 \mathrm{mb}\left(\# / \mathrm{cm}^{3}\right)$

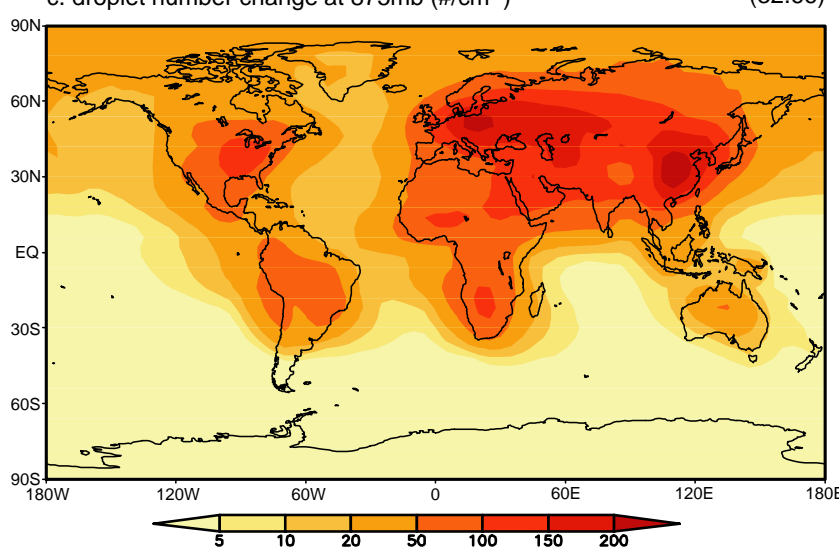

(32.66) d. indirect aerosol forcing $\left(\mathrm{W} / \mathrm{m}^{2}\right)$

$(-1.30)$

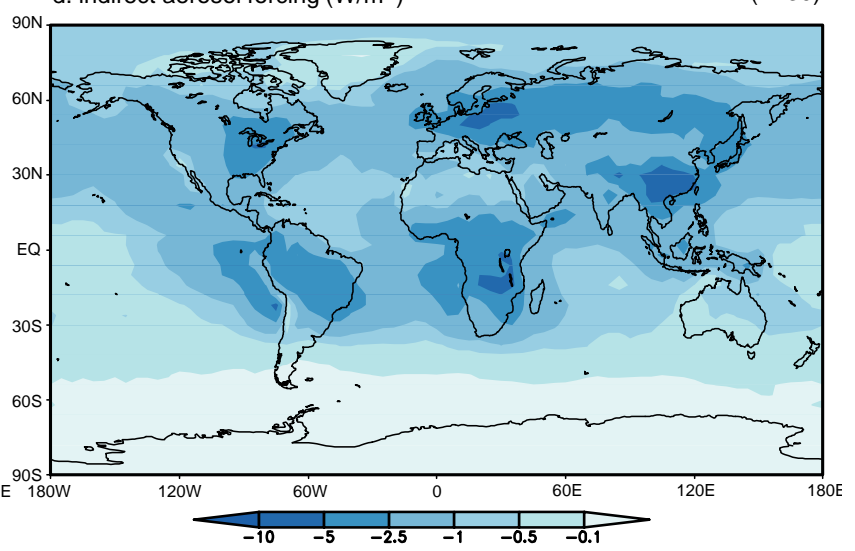

Fig. 3. (a) Annual mean anthropogenic aerosol burden. (b) Annual mean natural aerosol burden. (c) Annual mean cloud droplet change at $875 \mathrm{mb}$ level from PI to PD. (d) Four-month (Jan, Apr, Jul, Oct) mean aerosol indirect forcing from the reference case. The numbers in the parentheses give the global mean values.

The largest anthropogenic aerosol and droplet concentration changes are located in Europe, East Asia, North America, the African savanna, and the South America rainforest region. The former three are mainly related to aerosol emissions from fossil fuel use, and the latter two are related to carbonaceous aerosol emissions from biomass burning. Note that the marine regions near these regions also have a large forcing, which is related to the small value of the pre-industrial aerosol concentration in these areas (Fig. 3b) and the small surface albedo over the ocean. The global mean value for the first indirect effect in the reference case is $-1.30 \mathrm{Wm}^{-2}$ which is within the range reported in literature, summarized by Suzuki et al. (2004) (i.e., -0.5 to $-1.6 \mathrm{Wm}^{-2}$ ).

\subsection{Cloud droplet number and effect radius}

The change in the aerosol concentrations between the PD and PI cases causes a change in the cloud droplet number concentration. However, due to the spatial distribution of natural and anthropogenic aerosols, the change in the droplet concentration also varies with region. Figure 4a shows the change in the LWC-weighted in-cloud droplet concentrations over the SH ocean, SH land, NH ocean and NH land for different perturbation cases. A general characteristic is that the change of $N_{d}$ over land is more than that over ocean, and it is larger in the $\mathrm{NH}$ than in the $\mathrm{SH}$.

In the first indirect effect, aerosols change the radiative balance by modifying the cloud droplet effect radius $\left(r_{e}\right)$. Therefore, we show the change in $r_{e}$ after the addition of the anthropogenic aerosols in Fig. 4b. In most cases, the present day global average $r_{e}$ is about $0.5 \mu \mathrm{m}$ smaller than the preindustrial value. Moreover, the change is much larger over land $(\sim 0.8 \mu \mathrm{m})$ than over ocean $(\sim 0.25 \mu \mathrm{m})$, which is quite reasonable considering that there are larger anthropogenic aerosols over land. Over the ocean, the decrease in $r_{e}$ in the northern hemisphere is clearly larger than that in the southern hemisphere in all cases. Over the land, however, there is no clear signature of the change between the southern hemisphere and the northern hemisphere for all cases. 
Table 3. Cloud droplet effective radius $(\mu \mathrm{m})$ from model simulation and from satellite measurements: ISCCP (Han et al., 1994) and MODIS (King et al., 1997).

\begin{tabular}{lcccc}
\hline & NH land & SH land & NH ocean & SH ocean \\
\hline Reference & 5.12 & 6.00 & 6.68 & 7.50 \\
MAX_EMI & 4.97 & 5.81 & 6.56 & 7.42 \\
MIN_EMI & 5.24 & 6.10 & 6.76 & 7.55 \\
MAX_R & 6.84 & 8.61 & 7.49 & 8.52 \\
MIN_R & 14.31 & 8.71 & 5.96 & 6.56 \\
MAX_SG & 6.25 & 7.66 & 7.56 & 8.53 \\
MIN_SG & 5.00 & 5.14 & 6.01 & 6.71 \\
DIST_PI & 5.12 & 6.00 & 6.68 & 7.50 \\
MAX_MA & 4.53 & 5.04 & 5.40 & 5.92 \\
MIN_MA & 7.03 & 8.77 & 10.65 & 12.00 \\
W_TKE & 4.71 & 5.19 & 5.45 & 5.88 \\
PARA_NS & 5.32 & 6.05 & 6.78 & 7.56 \\
PARA_CP & 5.58 & 6.78 & 7.92 & 9.09 \\
BC_INC & 5.12 & 6.00 & 6.68 & 7.50 \\
MAX_LWP & 6.30 & 7.38 & 8.21 & 9.22 \\
MIN_LWP & 4.79 & 5.61 & 6.25 & 7.02 \\
MIN_CF & 5.12 & 6.00 & 6.68 & 7.50 \\
$\beta$ FNDD & 5.88 & 6.70 & 7.42 & 8.23 \\
$\beta$ _RLlow & 5.34 & 6.11 & 6.77 & 7.52 \\
$\beta$ _RLup & 6.86 & 7.62 & 8.28 & 9.00 \\
$\beta$ _RLmid & 5.99 & 6.67 & 7.33 & 8.02 \\
ISCCP & 8.2 & 9 & 11.6 & 12 \\
MODIS & 7.2 & 8.3 & 10.9 & 10.5 \\
\hline
\end{tabular}

\subsection{TOA forcing}

The zonal mean forcing from the simulations of the perturbation cases is shown on Fig. 5. The perturbation cases have been divided into several groups to compare them to the results of the reference case. These groups are shown on different panels on Fig. 5. Table 4 gives the forcing from each of the cases and Fig. 6 shows the change in global average forcing from the reference case.

Figure 5a shows that the uncertainty associated with aerosol and aerosol precursor emissions is very large. This is because the range of anthropogenic emissions themselves is very large, e.g. the global $\mathrm{SO}_{2}$ emission range is from 67 to $130 \mathrm{TgS} / \mathrm{Yr}$ (Penner et al., 2001). The forcing in the MAXEMI case $\left(-1.63 \mathrm{Wm}^{-2}\right)$ is larger than in the reference case $\left(-1.30 \mathrm{Wm}^{-2}\right)$ because the difference in aerosol concentration from the PI to PD increases since the PI aerosol concentrations remain constant.

Changes associated with changes in the aerosol concentration are shown in Fig. 5b. In the MAX_MA case, the maximum aerosol mass concentration in both the PD and PI cases from the model inter-comparison was used. Both the $\mathrm{PI}$ and PD aerosol number concentrations increase compared to those in the REFERENCE case. But since the relationship between the droplet number $\left(N_{d}\right)$ and the aerosol num-
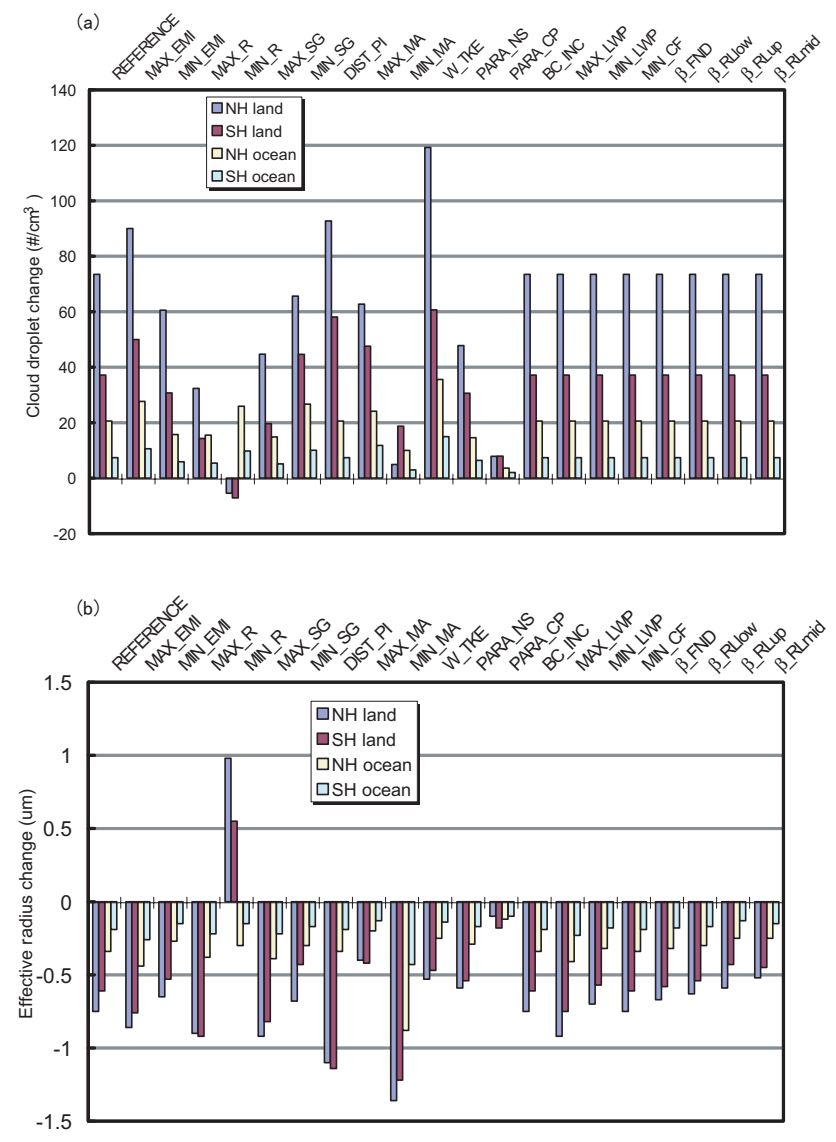

Fig. 4. (a) Global mean cloud droplet number concentration change from PI to PD. (b) Global mean cloud effective radius change from PI to PD.

ber $\left(N_{a}\right)$ is non-linear, $N_{d}$ changes faster than $N_{a}$ when the value of $N_{a}$ is smaller as in the PI case. Therefore, compared to the REFERENCE case, the $N_{d}$ difference between PI and PD is smaller in the MAX_MA case. And the forcing in MAX_MA case is smaller (i.e. $-0.94 \mathrm{Wm}^{-2}$ compared to $-1.30 \mathrm{Wm}^{-2}$ ). Similarly, due to the non-linear relationship between $N_{d}$ and $N_{a}$, the $N_{d}$ difference between PI and $\mathrm{PD}$ and the forcing in MIN_MA case are larger than those in the REFERENCE case (i.e. $-2.16 \mathrm{Wm}^{-2}$ compared to $-1.30 \mathrm{Wm}^{-2}$ ).

The effect of changes in the aerosol size distribution is shown in Fig. 5c. The change in the aerosol size distribution modifies the total aerosol number concentration calculated based on the fixed mass concentration. It also affects the fraction of aerosols that are activated to droplets because large aerosols activate more easily than smaller aerosols. Increasing the aerosol mode radius (MAX_R) reduces the total aerosol number concentration, thereby reducing the forcing $\left(-1.25 \mathrm{Wm}^{-2}\right)$. But the forcing change is small, and most of the change is in the northern hemisphere. Decreasing the mode radius (MIN_R) increases the total aerosol number. However, the indirect forcing calculated from the 

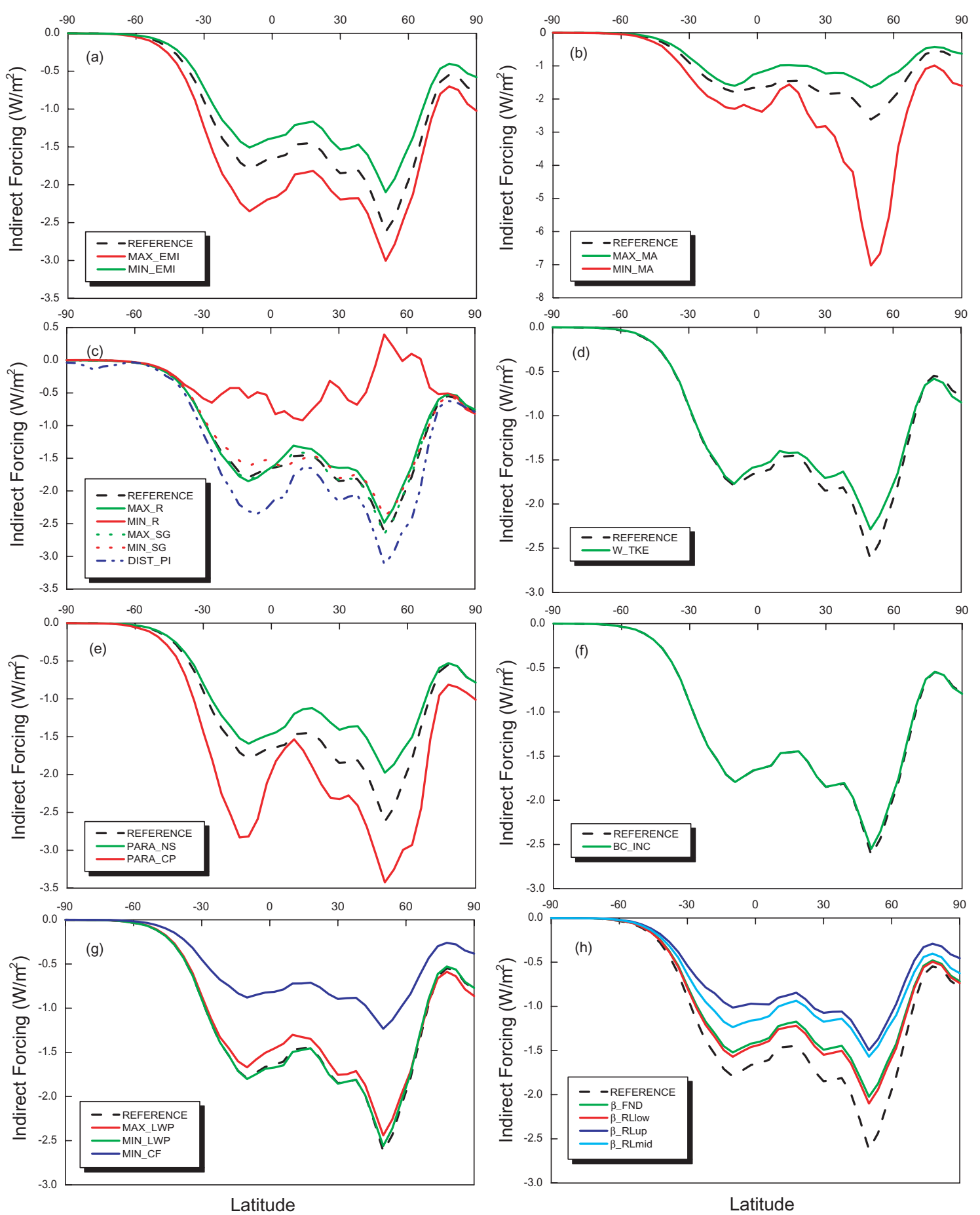

Fig. 5. Zonal mean indirect aerosol forcing results from different cases.

MIN_R case $\left(-0.45 \mathrm{Wm}^{-2}\right)$ is much smaller than that in the reference case $\left(-1.30 \mathrm{Wm}^{-2}\right)$. This is because in MIN_R case, the aerosol mode radius is very small, which causes extremely high aerosol number concentration (calculated from the fixed mass concentration and size distribution), especially over the continents. This high concentration can not exist in the real atmosphere for a long time because small aerosols with high number concentrations coagulate very quickly and transform to the accumulation mode in a very short time. We calculate on average e-folding time for coagulation of $300 \mathrm{~s}$ over the continents given the concentrations calculated for this case. If this high concentration did exist, the addition of 
Table 4. Global average indirect aerosol forcing from different perturbation cases.

\begin{tabular}{lc}
\hline Case & Forcing $\left(\mathrm{W} / \mathrm{m}^{2}\right)$ \\
\hline Reference & -1.30 \\
MAX_EMI & -1.63 \\
MIN_EMI & -1.06 \\
MAX_R & -1.25 \\
MIN_R & -0.45 \\
MAX_SG & -1.30 \\
MIN_SG & -1.24 \\
DIST_PI & -1.60 \\
MAX_MA & -0.94 \\
MIN_MA & -2.16 \\
W_TKE & -1.23 \\
PARA_NS & -1.07 \\
PARA_CP & -1.79 \\
BC_INC & -1.29 \\
MAX_LWP & -1.21 \\
MIN_LWP & -1.30 \\
MIN_CF & -0.63 \\
$\beta$ _FND & -1.07 \\
$\beta$ _RLlow & -1.10 \\
$\beta$ _RLup & -0.75 \\
$\beta$ _RLmid & -0.86 \\
\hline
\end{tabular}

more aerosols will decrease the number of nucleated cloud droplets due to their competition for water vapor. This can be seen from the parcel model simulation. Figure B1 shows that above a certain aerosol number concentration, the cloud droplet number decreases with $N_{a}$. Nevertheless, we do not consider this case to be realistic, and therefore do not include it in our estimates of the most important uncertainty.

The MAX_SG curve and MIN_SG curve are very close to those in the REFERENCE case, which implies that the forcing is insensitive to the choice of $\sigma$ if the same $\sigma$ is used in both the PD and PI simulations. However, if a different size distribution is used in the PD and PI cases, the sensitivity of the indirect forcing is very high. When we use the free troposphere aerosol size distribution as the PI aerosol size distribution, the indirect forcing increases substantially (i.e., $-1.60 \mathrm{Wm}^{-2}$ compared to $-1.30 \mathrm{Wm}^{-2}$ ), because the droplet number concentration in the PI case is decreased.

Changes in the forcing associated with the method of computing the updraft velocity are shown in Fig. 5d. Compared to the PDF method of calculating updraft velocity $(w)$, the forcing calculated using the TKE method for estimating $w$ is smaller (i.e., $-1.23 \mathrm{Wm}^{-2}$ compared to $-1.30 \mathrm{Wm}^{-2}$ ). By comparing the cloud droplet number concentration from the PI and PD cases, we find that when using the TKE method for $w$, the $N_{d}$ is larger than that when using the PDF method in most regions. However, the combined effect of changing the method for calculating $w$ on both the PI and PD droplet concentration causes the forcing calculated by using the TKE method to be smaller than that using the PDF method.

Figure 5e shows the effect of changing the method of parameterizating the relationship between $N_{a}$ and $N_{d}$. The pattern of forcing obtained using the NS parameterization is very similar to that in the reference case (AG3 parameterization), though the forcing value $\left(-1.07 \mathrm{Wm}^{-2}\right)$ is smaller when using the NS parameterization. The reason is that when the aerosol number is small, the NS parameterization produces more $N_{d}$ than does the AG3 parameterization, and when the aerosol number is large, the NS parameterization produces less $N_{d}$ (see Appendix A). The results from the CP parameterization are very different. For most regions, the $N_{d}$ and forcing value are larger than those in the reference case. The reason is that the $N_{d}$ from low $N_{a}$ is much smaller than that in the reference case (see Appendix A), while the $N_{d}$ from high $N_{a}$ is similar to that in the reference case. Because the $\mathrm{CP}$ parameterization assumes a change in the aerosol size distribution between the PD and PI cases, it incorporates some of the uncertainty associated with the change in PD size (i.e., the change in the forcing $\left(-1.79 \mathrm{Wm}^{-2}\right)$ is similar to the change in forcing associated with case DIST_PI, which was $-1.60 \mathrm{Wm}^{-2}$ ). Both AG3 and NS parameterization are sectional resolved methods, so their patterns are more similar than those of the CP parameterization.

Figure $5 \mathrm{f}$ shows the effect of including the change in droplet single scattering albedo due to $\mathrm{BC}$ within the cloud. The forcing decreases after including the effect of $\mathrm{BC}$ within the clouds. The global mean difference in the forcing is $+0.01 \mathrm{Wm}^{-2}$, which is smaller than the results reported by Chuang et al. (2002). This change is small compared to the other factors considered here, but in those regions with high $\mathrm{BC}$ concentration and high cloud fraction, the impact of this change is more important.

Figure $5 \mathrm{~g}$ shows the effect of changing the LWP and CF. Changing the LWP will not change the number of cloud droplets but will change the effective radius in the cloud. A change in the LWC of the cloud $(\Delta q)$ will lead to a change of $(\Delta q)^{1 / 3}$ in effective radius. However, since the relative change of effective radius is not too different in the PD and PI cases, the forcing differences are small $\left(<0.1 \mathrm{Wm}^{-2}\right)$. The change in the cloud fraction (CF) does not change $N_{d}$ or $r_{e}$, but will change the reflected solar radiation. The forcing is very sensitive to $\mathrm{CF}$. The minimum $\mathrm{CF}$ produces less than $1 / 2$ the forcing of the reference case. We notice that the CF for total clouds from the reference parameterization is higher than that in the satellite observations, but it is similar to the MODIS warm cloud fraction. Thus we believe that the estimated forcing of the REFERENCE case $\left(-1.30 \mathrm{Wm}^{-2}\right)$ is close to that which would be calculated with these higher observed CFs. It is important to note that the cloud fraction is a major source of uncertainty in the calculation of the indirect aerosol forcing. The forcing is decreased to $-0.63 \mathrm{Wm}^{-2}$ in this case. 


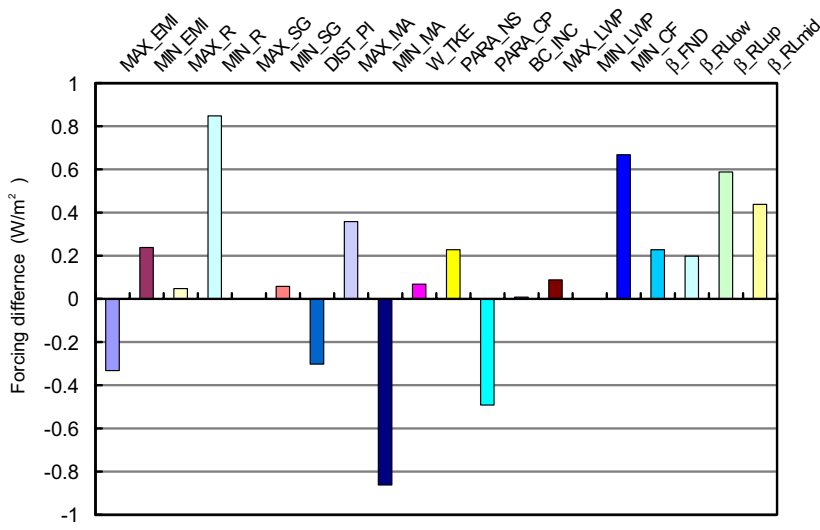

Fig. 6. The global mean indirect forcing difference compared to REFERENCE case.

Most GCM-based calculations of indirect forcing do not consider the effect of cloud drop dispersion. The relationship between the effective radius and the droplet number is often represented by a coefficient between volume mean radius and effective radius (Martin et al.,1994). However, our results show that the change in the indirect forcing associated with changing from the fixed coefficient $\beta$ to a $\beta$ that is related to $N_{d}$ is of some importance. The global mean change of indirect forcing after considering the dispersion effect using the method employed in Penner et al. (2004) is $0.23 \mathrm{Wm}^{-2}$, and the uncertainty due to the different representations of this dispersion effect in Rotstayn and Liu (2003) is $0.2 \sim 0.4 \mathrm{Wm}^{-2}$. These results compare well with those reported by Rostayn and Liu (2003) and Peng and Lohmann (2003).

To summarize the effect of different perturbations, we show the relative difference from different cases to the forcing from the reference case in Fig. 6. This can be used to analyze the major sources of uncertainty in the estimation of indirect aerosol radiative forcing. From the plot, we can see the uncertainty associated with the aerosol mass concentration is very large, and can increase the forcing by almost $0.8 \mathrm{Wm}^{-2}$. The uncertainty associated with cloud fraction is next in importance, followed by the uncertainty associated with the treatment of dispersion of the cloud drops.

The aerosol and aerosol precursor emissions, aerosol mean radius, updraft velocity, droplet parameterization method, and natural aerosol size also have some influence $\left(0.2 \sim 0.6 \mathrm{Wm}^{-2}\right)$ on the indirect forcing. The aerosol size standard deviation, BC effect on cloud albedo, and LWP have a relatively small effect on the simulated global average forcing.

\subsection{The uncertainty distribution}

By varying the above uncertainty sources, we can calculate the global indirect aerosol forcing for different cases, thereby estimating the 2-D distributions of the uncertainty. The un- (a) Uncertainty of the indirect forcing $\left(\mathrm{W} / \mathrm{m}^{2}\right)$

(1.82)

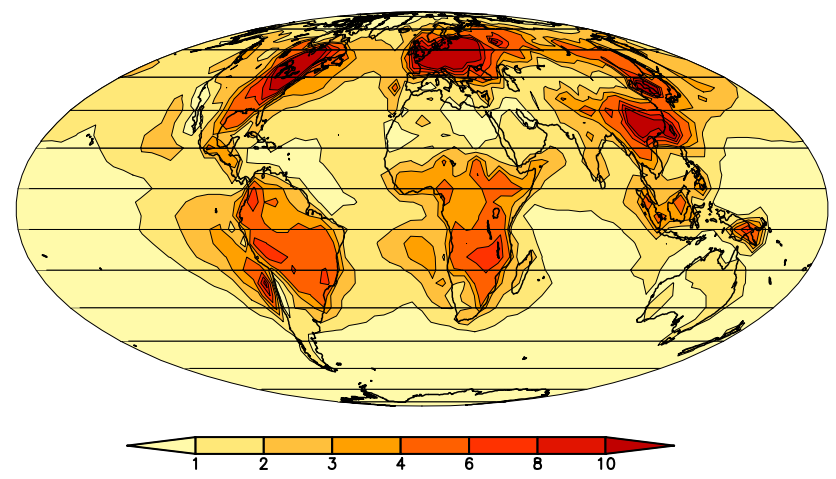

(b) Relative uncertainty of the indirect forcing

(1.3)

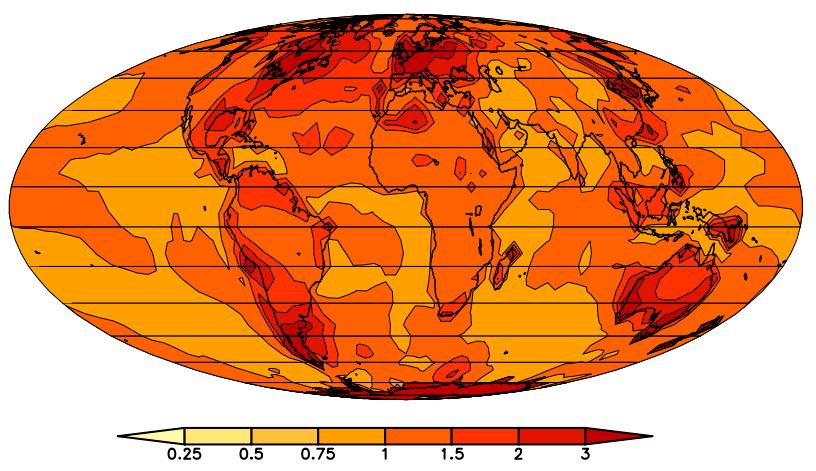

Fig. 7. The global indirect forcing uncertainty. (a) Absolute uncertainty $\left(\mathrm{Wm}^{-2}\right)$. (b) Relative uncertainty. The numbers in the parentheses give the global mean values.

certainty in the forcing can be estimated from

$\left(F-F_{0}\right)^{2}=\sum_{i}\left[\frac{\partial F}{\partial x_{i}}\right]^{2}\left(\partial x_{i}\right)^{2}+\sum_{i} \sum_{j} \operatorname{cov}\left(x_{i}, x_{j}\right)\left[\frac{\partial F}{\partial x_{i}}\right]\left[\frac{\partial F}{\partial x_{j}}\right]$

where $\left(F-F_{0}\right)^{2}$ is the variance in the forcing, so $\left|F-F_{0}\right|$ is the uncertainty. $x_{i}$ refers to the list of uncertain variables, and $\left(\partial x_{i}\right)^{2}$ is the variance in the variable $x_{i}$. The function $\operatorname{cov}\left(x_{i}, x_{j}\right)$ is the covariance of the variables in the argument. In our preliminary calculations of the spatial distribution of the uncertainty, the covariance between the preindustrial forcing and present forcing is omitted (Penner et al., 2001).

In the calculation of uncertainty associated with aerosol and aerosol precursor emissions, aerosol mass, aerosol size standard deviation, cloud nucleation parameterization method, LWP, and the cloud drop dispersion coefficient $\beta$, we assume that the maximum difference between REFERENCE and other cases (e.g. MAXIMUM or MINIMUM) is a measure of the $1 \sigma$ uncertainty associated with that source. For the uncertainty associated with the aerosol mode radius, 


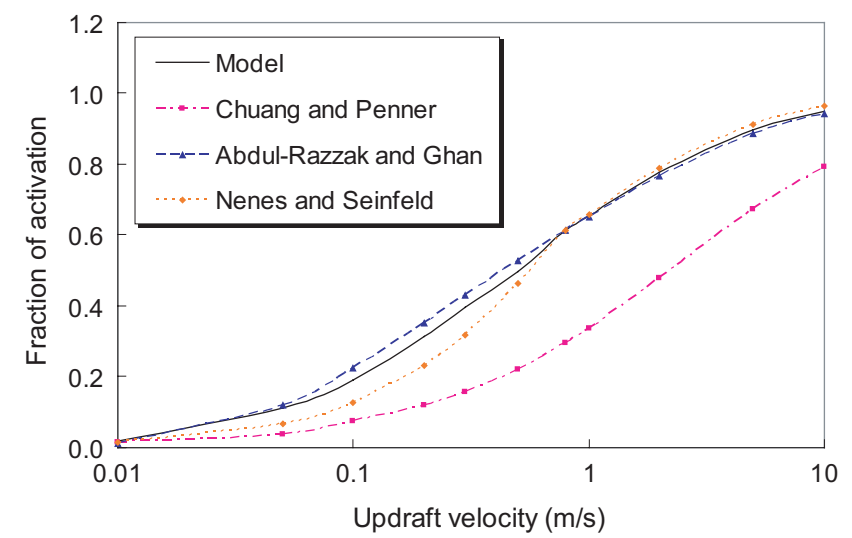

Fig. A1. Comparison of $N_{d}$ from the three parameterizations and the parcel model.

only the results from the maximum mode radius are used since in the MIN_R case, there were unrealistically small aerosol sizes and large $N_{a}$. For all other cases, the difference between reference case and perturbation case is considered. Figure 7 shows that the largest values of absolute uncertainty occur in the same regions that have the highest indirect forcing. However, the largest relative values of the uncertainty are mostly over the ocean areas that are closest to continent regions with high aerosol indirect forcing. The global average relative uncertainty in indirect aerosol forcing is about $130 \%$. This value is in reasonable agreement with that based on the range in GCM assessments (Ramaswami, 2001) and with box model calculations (Penner et al. 2001).

\section{Conclusions and Discussion}

In this paper we analyzed the uncertainties in the model calculation of aerosol forcing associated with the first indirect effect. We have used a radiative transfer model to study the role of each uncertainty source in the aerosol effect on clouds. The aerosol burden calculated by chemical transport models and the cloud fraction are found to be the most important sources of uncertainty. A 2-D distribution of the uncertainty in indirect forcing has been shown. The global mean value of the relative uncertainty is about $130 \%$. The highest absolute uncertainty occurs in high anthropogenic aerosol emission regions, while the highest relative uncertainty occurs in coastal regions near these high anthropogenic aerosol emissions regions.

It appears from our simulation that the representation of the pre-industrial aerosol size distribution plays an important role in the calculation of anthropogenic aerosol forcing. A different selection of the pre-industrial aerosol size distribution causes a larger forcing because the cloud droplet number of the PI case decreases. This is consistent with the result by Platnick and Twomey (1994), which states that the cloud susceptibility (defined as the increase in albedo result-

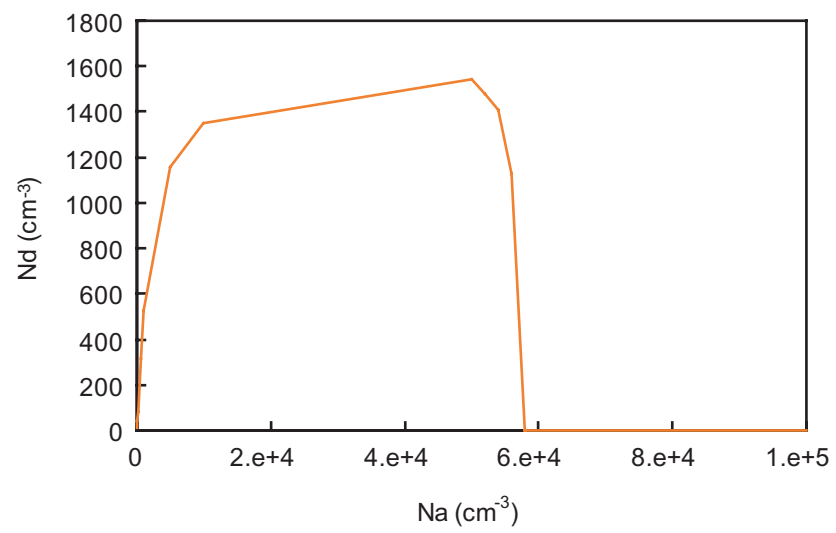

Fig. B1. The parcel model results showing the decrease of $N_{d}$ as $N_{a}$ increases when $N_{a}$ is very high.

ing from the addition of one cloud droplet per cubic centimeter for a constant cloud liquid water content) is larger when the droplet number is smaller. The uncertainty due to the pre-industrial aerosol mass concentration is also important.

One important aspect that was omitted in this study is the possible covariance between variables (cf. Eq. 1). Penner et al. (2001) found that the uncertainty was reduced when the covariance between the cloud albedo calculated for the present-day case and the pre-industrial case was taken into account. As in Penner et al. (2001), the correlation with the spatial and temporal distribution may be estimated by calculating the correlation in the outgoing shortwave radiation for matched pairs of the change in $N_{d}$ in the pre-industrial and present-day scenarios. The calculation of the effect of this correlation on the total uncertainty is ongoing work.

We note that the uncertainty of the first indirect effect was based on the model and the criteria used in this study. If a different radiative transfer model was used, or if other choices of criteria such as model resolution, cloud overlap scheme, or the aerosol mixing scheme were selected, the estimated uncertainty would probably be different.

The off-line simulation in the present study could cause other uncertainties since we used the monthly average aerosol number concentration from the IPCC model intercomparison study. A fully coupled GCM would give us a better estimation of the interactions of aerosols, clouds and radiation. In addition, the use of a GCM can take into account some of the cloud feedbacks due to the aerosol change (i.e. the second indirect effect), so it may be used to assess the second indirect aerosol forcing. Ongoing work is also concerned with assessing the uncertainty associated with these feedbacks.

\section{Appendix A}

The fraction of activated aerosols $\left(N_{d} / N_{a}\right)$ calculated from three mechanistic parameterizations has been compared to 
that from a size-resolved cloud nucleation parcel model (Liu and Seidl, 1998). In the comparison, the total aerosol number concentration is set to be $1000 \mathrm{~cm}^{-3}$. The size distribution is assumed to be a single log-normal distribution with a mode radius of $0.05 \mu \mathrm{m}$ and a standard deviation of 2 . The aerosols are pure ammonium sulfate. Because the results of the AG3 parameterization were closest to those from the parcel model, we used the AG3 parameterization in our reference case.

\section{Appendix B}

The cloud droplet number concentration can be simulated from a cloud nucleation parcel model. In the simulation, the updraft velocity is $50 \mathrm{~cm} / \mathrm{s}$. The size distribution is assumed to be a single log-normal distribution with a mode radius of $0.05 \mu \mathrm{m}$ and a standard deviation of 2 .

Acknowledgements. This study was supported by the NASA ACMAP program. Partial support from the DOE ARM program is also gratefully acknowledged. We would like to thank Stefan Kinne for providing MODIS effective radius data.

Edited by: U. Lohmann

\section{References}

Abdul-Razzak, H. and Ghan, S. J.: A parameterization of aerosol activation, 3. Sectional representation, J. Geophys. Res., 107, D3(4026), doi:10.1029/2001JD000483, 2002.

Ackerman, A. S., Toon, O. B., Stevens, D. E., Heymsfield, A. J., Ramanathan, V., and Welton, E. J.: Reduction of tropical cloudiness by soot, Science, 245, 1227-1230, 1989.

Albrecht, B. A.: Aerosols, cloud microphysics, and fractional cloudiness, Science, 245, 1227-1230, 1989.

Andronache, C., Donner, L. J., Seman, C. J., Ramaswamy, V., and Hemler, R. S.: Atmospheric sulfur and deep convective clouds in tropical pacific: A model study, J. Geophys. Res., 104, 40054024, 1999.

Boucher, O. and Lohmann, U.: The sulfate-CCN-cloud albedo effect: A sensitivity study using two general circulation models, Tellus, Ser. B, 47, 281-300, 1995.

Chuang, C. C., Penner, J. E., Taylor, K. E., Grossman, A. S., and Walton, J. J.: An assessment of the radiative effects of anthropogenic sulfate, J. Geophys. Res., 102, 3761-3778, 1997.

Chuang, C. C., Penner, J. E., Prospero, J. M., Grant, K. E., Rau, G. H., and Kawamoto, K.: Cloud susceptibility and the first aerosol indirect forcing: Sensitivity to black carbon and aerosol concentrations, J. Geophys. Res., 107, doi:10.1029/2000JD000215, 2002.

Conant, W. C., Nenes, A., and Seinfeld, J. H.: Black carbon radiative heating effects on cloud microphysics and implications for the aerosol indirect effect. 1. Extended Köhler theory. J. Geophys. Res., 107, 4604, doi:10.1029/2002JD002094, 2002.

Feingold, G. and Heymsfield, A. J.: Parameterizations of condensational growth of droplets for use in General Circulation Models, J. Atmos. Sci., 49, 2325-2342, 1992.
Feng, Y., Penner, J. E., Sillman, S., and Liu, X. H.: Effects of cloud overlap in photochemical models, J. Geophys. Res., 109, D04310, doi:10.1029/2003JD004040, 2004.

Geleyn, J. F. and Hollingsworth, A.: An economical analytical method for the computation of the interaction between scattering and line absorption of radiation, Contrib. Atmos. Phys., 52, 1-16, 1979.

Ghan, S. J., Easter, R. C., Chapman, E. G., Abudul-Razzak, H., Zhang, Y., Leung, L. R., Laulainen, N. S., Saylor, R. D., and Zaveri, R. A.: A physically based estimate of radiative forcing by anthropogenic sulfate aerosol, J. Geophys. Res., 106, 52795293, 2001.

Graß1, H.: Possible changes of planetary albedo due to aerosol particles, in: Man's Impact on Climate, edited by: Bach, K., Pankrath, Elsevier, Amsterdam, 1979.

Greenwald, T. J., Stephens, G. L., Vonder Haar, T. H., and Jackson, D. L.: A physical retrieval of cloud liquid water over the global oceans using Special Sensor Microwave/Imager (SSM/I) observations, J. Geophys Res, 98, 18 471-18 488, 1993.

Hack, J.: Sensitivity of the simulated climate to a diagnostic formulation for cloud liquid water, J. Clim., 11(7), 1497-1515, 1998.

Han, Q., Rossow, W. B., and Lacis, A. A.: Near-global survey of effective droplet radii in liquid water clouds using ISCCP data, J. Clim., 7, 465-497, 1994.

Hansen, J., Sato, M., and Ruedy, R.: Radiative forcing and climate response, J. Geophys. Res., 102, 6831-6864, 1997.

Houghton, J. T., Ding, Y., Griggs, D. J., Noguer, M., Van der Linden, P. J., Dai, X., Maskell, K., and Johnson, C. A.: Climate Change 2001: The Scientific Basis, Contribution of working group I to the Third Assessment Report of the Intergovernmental Panel on Climate Change, Cambridge Univ. Press, New York, 2-20, 2001.

Iversen, T., Kirkevåg, A., Kristjánsson, J. E., and Seland, Ø.: Climate effects of sulphate and black carbon estimated in a global climate model, in: Air Pollution Modeling and its Application XIV, edited by: Gryning, S.-E. and Schiermeier, F. A., Kluwer Academic/Plenum Publishers, New York, 335-342, 2001.

Jones, A., Roberts, D. L., and Slingo, A.: A climate model study of indirect radiative forcing by anthropogenic sulphate aerosols, Nature, 370, 450-453, 1994.

Jones, A., Roberts, D. L., Woodage, M. J., and Johnson, C. E.: Indirect sulphate aerosol forcing in a climate model with an interactive sulphur cycle, J. Geophys. Res., 106, 20 293-20 310, 2001.

Kiehl, J. T., Schneider, T. L., Rasch, P. J., Barth, M. C., and Wong, J.: Radiative forcing due to sulfate aerosols from simulations with the National Center for Atmospheric Research Community Climate Model, Version 3, J. Geophys. Res., 105, 1441-1457, 2000.

King, M. D., Tsay, S.-C., Platnick, S. E., Wang, M., and Liou, K.N.: Cloud retrieval algorithms for MODIS: optical thickness, effective particle radius, and thermodynamic phase, MODIS Algorithm Theoretical Basis Document, No. ATBD-MOD-05, MOD06 - Cloud product, 1997.

Kristjánsson, J. E.: Studies of the aerosol indirect effect from sulfate and black carbon aerosols, J. Geophys. Res., 107(D15), doi:10.1029/2001JD000887, 2002.

Liu, X. and Seidl, W.: Modeling study of cloud droplet nucleation and in-cloud sulfate production during the Sanitation of the Atmosphere (SANA) 2 campaign, J. Geophys. Res., 103, $16145-$ 
$16158,1998$.

Liu, Y. G. and Daum, P. H.: Indirect warming effect from dispersion forcing, Nature, 419, 580-581, 2002.

Lohmann, U. and Feichter, J.: Impact of sulfate aerosols on albedo and lifetime of clouds: A sensitivity study with the ECHAM4 GCM, J. Geophys. Res., 102, 13 685-13 700, 1997.

Lohmann, U., McFarlane, N., Levkov, L., Abdella, K., and Albers, F.: Comparing different cloud schemes of a single column model by using mesoscale forcing and nudging techniquie, J. Clim., 12, 438-461, 1999a.

Lohmann, U., Feichter, J., Chuang, C. C., and Penner, J. E.: Prediction of the number of cloud droplets in the ECHAM GCM, J. Geophys. Res., 104, 9169-9198, 1999b.

Lohmann, U., Feichter, J., Penner, J., and Leaitch, R.: Indirect effect of sulfate and carbonaceous aerosols: A mechanistic treatment, J. Geophys. Res., 105, 12 193-12 206, 2000.

Lohmann, U. and Feichter, J.: Global indirect aerosol effects: a review, Atmos. Chem. Phys., 5, 715-737, 2005,

SRef-ID: 1680-7324/acp/2005-5-715.

Martin, G. M., Johnson, D. W., and Spice, A.: The measurement and parameterization of effective radius of droplets in warm stratiform clouds, J. Atmos. Sci., 51, 1823-1842, 1994.

Menon, S., Del Genio, A. D., Koch, D., and Tselioudis, G.: GCM simulations of the aerosol indirect effect: sensitivity to cloud parameterization and aerosol burden, J. Atmos. Sci., 59, 692-713, 2002.

Nenes, A. and Seinfeld, J. H.: Parameterization of cloud droplet formation in global climate models, J. Geophys. Res., 108, D14(4415), doi:10.1029/2002JD002911, 2003.

Paluch, I. R. and Lenschow, D. H.: Comment on "Measurements of aitken nuclei and cloud condensation nuclei in the marine atmosphere and their relation to the DMS-cloud-climate hypothesis" by Hegg, D. A., Radke, L. F., and Hobbs, P. V., J. Geophys. Res., 97, 7657-7658, 1992.

Peng, Y. and Lohmann, U.: Sensitivity study of the spectral dispersion of the cloud droplet size distribution on the indirect aerosol effect, Geophys. Res. Lett., 30, 10(1507), doi:10.1029/2003GL017192, 2003.

Penner, J. E., Andreae, M., Annegarn, H., Barrie, L., Feichter, J., Hegg, D., Jayaraman, Leaitch, R., Murphy, D., Nganga, J., and Pitari, G.: Aerosols, their Direct and Indirect Effects, in: Climate Change 2001: The Scientific Basis, Contribution of working group I to the Third Assessment Report of the Intergovernmental Panel on Climate Change, edited by: Houghton, J. T., Ding, Y., Griggs, D. J., Noguer, M., Van der Linden, P. J., Dai, X., Maskell, K., and Johnson, C. A., 881 pp., Cambridge Univ. Press, New York, 2001.

Penner, J. E., Zhang, S. Y., and Chuang, C. C.: Soot and smoke aerosol may not warm climate, J. Geophys. Res., 108, 4657, doi: 10.1029/2003JD003409, 2003.
Penner, J. E., Dong, X., and Chen, Y.: Observational evidence of a change in radiative forcing due to the indirect aerosol effect, Nature, 427, 231-234, 2004.

Penner, J. E.: Climate change - The cloud conundrum, Nature, 432, 962-963, 2004.

Platnick, S. and Twomey, S.: Determining the susceptibility of cloud albedo to changes in droplet concentration with the advanced very high resolution radiometer, J. Appl. Meteor., 33, 334-346, 1994.

Quaas, J., Boucher, O., and Bréon, F.-M.: Aerosol indirect effects in POLDER satellite data and Laboratoire de Météorologie Dynamique-Zoom (LMDZ) general circulation model, J. Geophys. Res., 109, D08205, doi:10.1029/2003JD004317, 2004.

Ramaswamy, V., Boucher, O., Haigh, J., Hauglustaine, D., Haywood, J., Myhre, G., Nakajima, T., Shi, G. Y., and Solomon, S.: Radiative Forcing of Climate Change, in: Climate Change 2001: The Scientific Basis, Contribution of working group I to the Third Assessment Report of the Intergovernmental Panel on Climate Change, edited by: Houghton, J. T., Ding, Y., Griggs, D. J., Noguer, M., Van der Linden, P. J., Dai, X., Maskell, K., and Johnson, C. A., 349-416, Cambridge Univ. Press, New York, 2001.

Roelofs, G., Lelieveld, J., and Ganzeveld, L.: Simulation of global sulfate distribution and the influence on effective cloud drop radii with a coupled photochemistry-sulfur cycle model, Tellus, Ser. B, 50, 224-242, 1998.

Rotstayn, L. D. and Liu, Y. G.: Sensitivity of the first indirect aerosol effect to an increase of cloud droplet spectral dispersion with droplet number concentration, J. Clim., 16, 3476-3480, 2003.

Rotstayn, L. D. and Penner, J. E.: Indirect aerosols forcing, quasi forcing, and climate response, J. Clim., 14, 2960-2975, 2001.

Sundqvist, H.: Parametrization of condensation and associated clouds in models for weather prediction and general circulation simulation, in: Physically-Based Modelling and Simulation of Climate and Climate Change, edited by: Schlesinger, M. E., Kluwer, 433-461, 1988.

Suzuki, K., Nakajima, T., Numaguti, A., Takemura, T., Kawamoto, K., and Higurashi, A.: A study of the aerosol effect on a cloud field with simultaneous use of GCM modeling and satellite observation, J. Atmos. Sci., 61, 179-193, 2004.

Twomey, S.: Pollution and the planetary albedo, Atmos. Environ., 8, 1251-1256, 1974.

Weng, F. and Grody, N. C.: Retrieval of cloud liquid water using the special sensor microwave imager (SSM/I), J. Geophys. Res., 99, 25 535-25 551, 1994.

Zhang, S. Y.: A study of soot and smoke aerosols and improved biomass smoke emissions using the TOMS AI, Ph.D dissertation, University of Michigan, 2003. 